\title{
Retalho fasciocutâneo bipediculado para tratamento de meningomieloceles
}

\author{
Bipedicled fasciocutaneous flap in the meningomyeloceles treatment
}

Trabalho realizado na Faculdade de Ciências Médicas da Santa Casa de Misericórdia de São Paulo, São Paulo, SP, Brasil.

Artigo submetido pelo SGP (Sistema de Gestão de Publicações) da RBCP.

Artigo recebido: 3/2/2010 Artigo aceito: 4/7/2010

\begin{abstract}
RESUMO
Introdução: Os defeitos congênitos do tubo neural e tecidos associados são classificados como disrafismos espinhais, sendo a meningomielocele a forma mais grave. Objetivos: Avaliar a eficácia do retalho fasciocutâneo bipediculado bilateral no tratamento das meningomieloceles. Método: A técnica foi utilizada em 9 pacientes com diagnóstico de meningomielocele, no período de dezembro de 2006 a janeiro de 2009. Os pacientes foram submetidos à correção cirúrgica nas primeiras 36 horas de vida, com atuação conjunta das equipes de Neurocirurgia e de Cirurgia Plástica. Resultados: Observou-se que a principal localização do defeito foi a região lombossacra $(77,78 \%)$, seguida da toracolombar $(11,11 \%)$ e torácica (11,11\%). Autilização do retalho fasciocutâneo bipediculado bilateral possibilitou o fechamento da lesão em todos os casos. O defeito apresentava, em média, $32,1 \mathrm{~cm}^{2}$. A única complicação observada nesta série foi a epiteliólise segmentar do retalho na linha média, observada em $1(11,1 \%)$ paciente. Discussão: A escolha do retalho fasciocutâneo bipediculado bilateral utilizada nos casos apresentados deve-se à segurança em relação à vascularização, menor tempo cirúrgico quando comparado aos retalhos musculares, facilidade da dissecção, aplicabilidade e baixos índices de complicação. Conclusão: O retalho fasciocutâneo bipediculado e bilateral é adequado para o tratamento das meningomieloceles.
\end{abstract}

Descritores: Disrafismo espinal. Meningomielocele. Retalhos cirúrgicos.

\section{SUMMARY}

Introduction: Neural tube defects and associated tissues are classified as spinal dysraphism, being the most severe one the meningomyelocele. Objectives: To evaluate the efficacy of the bilateral bipedicled fasciocutaneous flap in the meningomyeloceles treatment. Methods: Nine patients were operated on meningomyelocele from December 2006 to January 2009. The patients had a surgery correction performed in the first 36 hours of life, with the presence of Neurosurgery and Plastic Surgery teams. Results: The main location of the defect was in the lumbosacral region $(77.78 \%)$, followed by the thoracolumbar $(11.11 \%)$ and the thoracic one (11.11\%). In all the cases, the bilateral bipedicled fasciocutaneous flap was performed to close the defect. Discussion: The bilateral bipedicled fasciocutaneous flap was chosen owing to the security regarding vascularization, the shorter surgical time compared to muscles flaps, dissection facility, applicability and low rate of complications. Conclusion: The bilateral bipedicled fasciocutaneous flap is an adequate treatment for meningomyelocele.

Descriptors: Spinal dysraphism. Meningomyelocele. Surgical flaps.

1. Doutor pela Faculdade de Ciências Médicas da Santa Casa de Misericórdia de São Paulo; Cirurgião plástico da Santa Casa de Misericórdia de São Paulo.

2. Pós-graduando da Disciplina de Cirurgia Plástica da Santa Casa de Misericórdia de São Paulo.

3. Mestre em cirurgia plástica pela Faculdade de Ciências Médicas da Santa Casa de São Paulo; médico assistente da Santa Casa de Misericórdia de São Paulo.

4. Doutor pela Faculdade de Ciências Médicas da Santa Casa de São Paulo; Chefe da Disciplina de Cirurgia Plástica da Santa Casa de Misericórdia de São Paulo. 


\section{INTRODUÇÃO}

Defeitos congênitos do tubo neural e tecidos associados são classificados como disrafismos espinhais, sendo a meningomielocele (MMGC) a forma mais grave ${ }^{1-4}$.

Essas anomalias podem afetar a pele do dorso, a coluna vertebral, as meninges, as raízes nervosas espinhais, a medula e as vísceras abdominais. A ocorrência dessa multiplicidade de lesões é função direta das camadas embriológicas afetadas. Defeitos do ectoderma levam a malformações cutâneas no dorso, tais como hipoplasia de pele, hipertricose, nevos e seio dérmico. Os defeitos do mesoderma determinam displasia de vértebras e as alterações do neuroderma acarretam desde a ausência de medula, até duplicação (diplomielia) e crescimento de tecidos não nervosos, como lipomas, angiomas e cistos ${ }^{1-4}$.

A etiologia dos defeitos do tubo neural é variável, envolvendo fatores genéticos e ambientais. A deficiência de folato durante as primeiras semanas de gestação foi implicada como um fator de risco. Há maior prevalência de casos em famílias que já tenham alguma criança previamente acometida. A frequência varia em diferentes grupos étnicos, predominando na raça branca e em indivíduos de classe social baixa ${ }^{3-5}$. O diagnóstico pré-natal foi facilitado pelos novos métodos de imagem, trazendo consigo a possibilidade de intervenção cirúrgica intraútero ${ }^{3,4}$.

A região lombossacral é envolvida em aproximadamente $75 \%$ dos casos, estando associada a déficit motor e sensitivo dos membros inferiores, bexiga e trato gastrointestinal baixo ${ }^{4,6}$.

A maioria das MMGC, após reparo neurocirúrgico, apresenta defeitos cutâneos pequenos e passíveis de síntese primária e sem tensão, com aproximação das bordas na linha média. Para os defeitos maiores que $5 \mathrm{~cm}$, que dificilmente podem ser fechados por sutura primária, são necessários métodos complementares ${ }^{4-6}$. Patterson ${ }^{5}$, em uma revisão de 130 casos, observou que, em $25 \%$ dos casos, não era possível a sutura primária, sendo necessária a utilização de técnicas cirúrgicas auxiliares.

$\mathrm{O}$ reparo do defeito, nesses pacientes, baseia-se em enxertos de pele, retalhos cutâneos, fasciocutâneos, musculares e musculocutâneos, e deve ser realizado de forma precoce, para diminuir a ocorrência de infecção no sistema nervoso central ${ }^{1,2,4,6}$. Nos pacientes não tratados, a mortalidade pode chegar a $65-75 \%$ nos primeiros seis meses $^{6}$.

O objetivo deste trabalho é avaliar a eficácia, descrever as indicações e a técnica cirúrgica do retalho fasciocutâneo bipediculado bilateral (RFCBB) para o tratamento das MMGC.

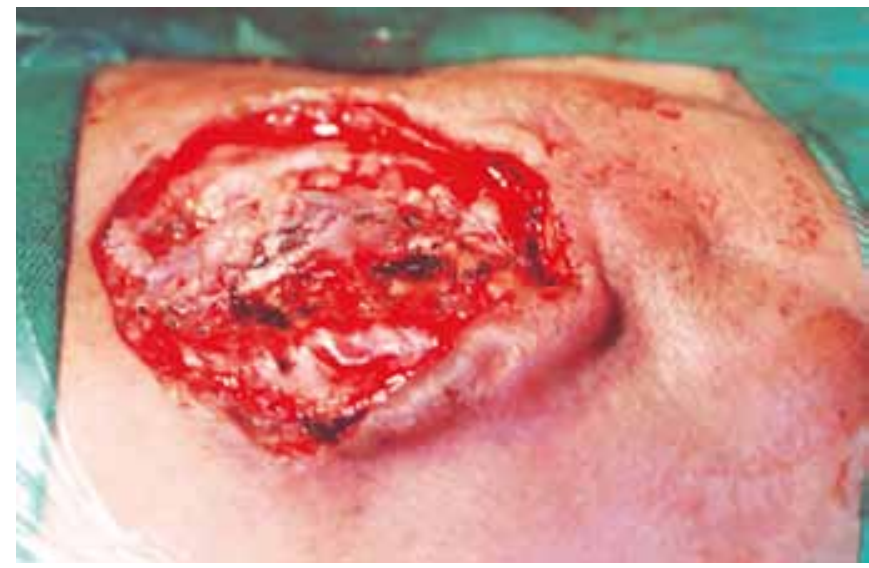

Figura 1 - Aspecto do defeito previamente ao fechamento dos elementos neurais, pela equipe da Neurocirurgia.

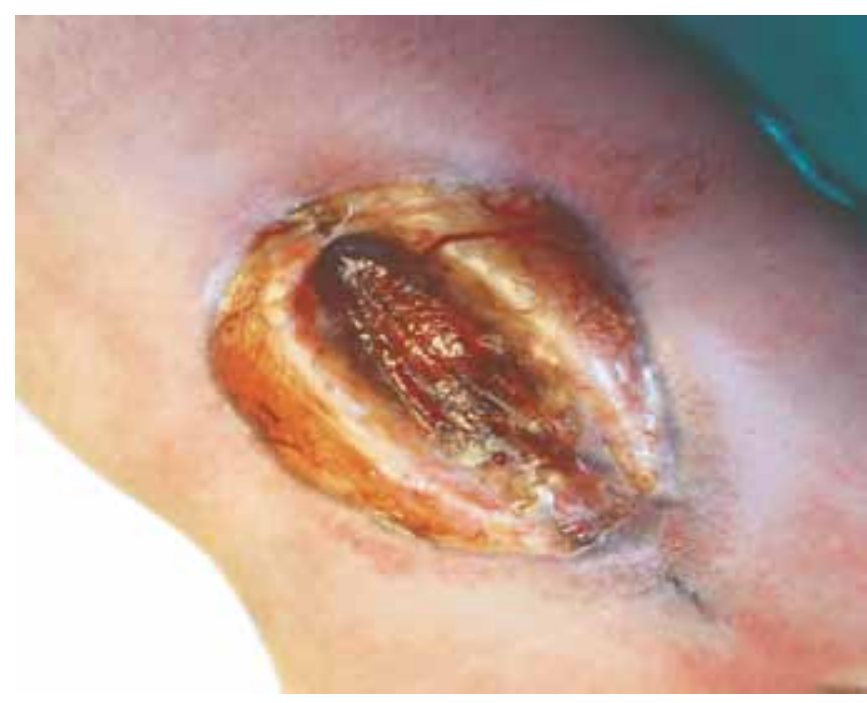

Figura 2 - Aspecto do defeito, após preservação dos elementos neurais e sutura da dura-máter pela equipe da Neurocirurgia.

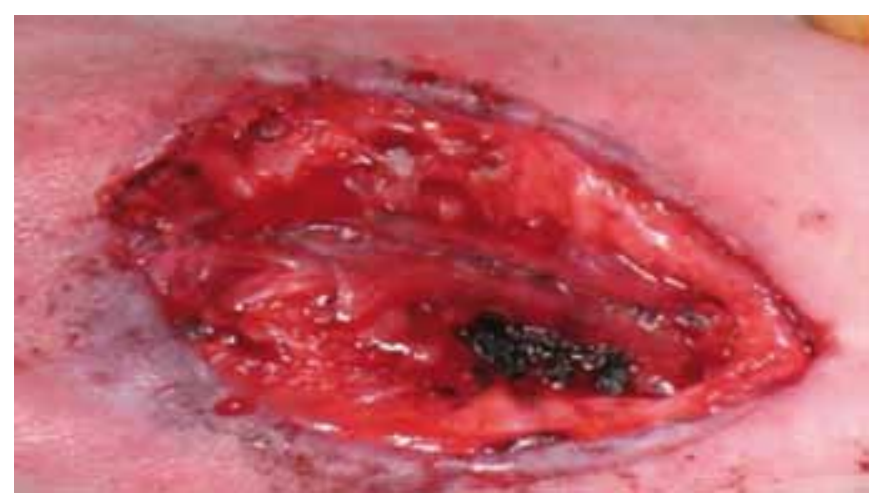

Figura 3 - Realização da mensuração do defeito a ser reparado. 


\section{MÉTODO}

O RFCBB foi utilizado em 9 pacientes operados com diagnóstico de MMGC, no período de dezembro de 2006 a janeiro de 2009. Em todos os casos, não havia a possibilidade de sutura primária da lesão. Foram avaliados: sexo, tipo de parto, diagnóstico pré-natal, doenças associadas, tamanho do defeito, tempo cirúrgico e complicações.

Os pacientes foram submetidos à correção cirúrgica nas primeiras 36 horas de vida, com atuação conjunta das equipes de Neurocirurgia e Cirurgia Plástica. A abordagem foi inicialmente realizada pela equipe da Neurocirurgia, preservandose os elementos neurais e realizando-se o fechamento da dura-máter. O RFCBB foi realizado pela equipe de Cirurgia Plástica (Figuras 1 e 2).

\section{Técnica Cirúrgica}

- Após término do procedimento neurocirúrgico, foram realizados os seguintes procedimentos:

- Paciente mantido em decúbito ventral e sob anestesia geral;

- Mensuração do defeito com régua milimetrada (Figura 3);

- Demarcação dos retalhos;

- Incisões longitudinais com cerca de $8 \mathrm{~cm}$ de extensão, entre a linha axilar média e posterior, bilateralmente (Figura 4);

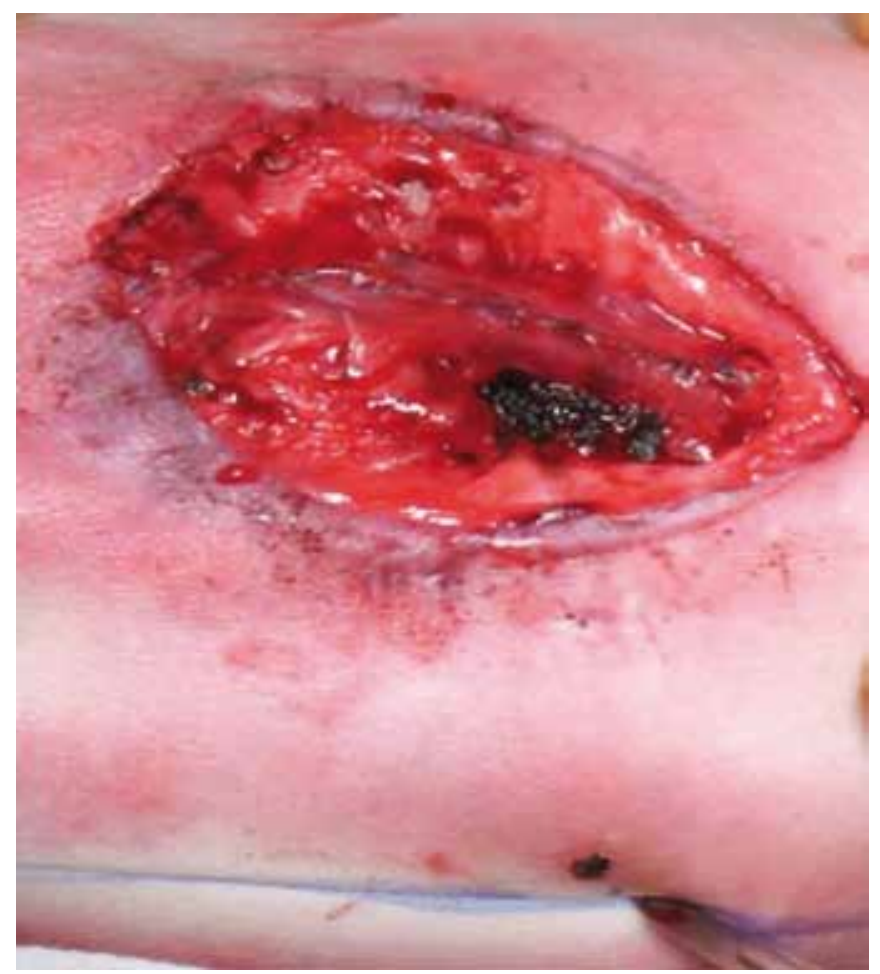

Figura 4 - Incisão do retalho na região lateral, na projeção da linha axilar média para posterior.

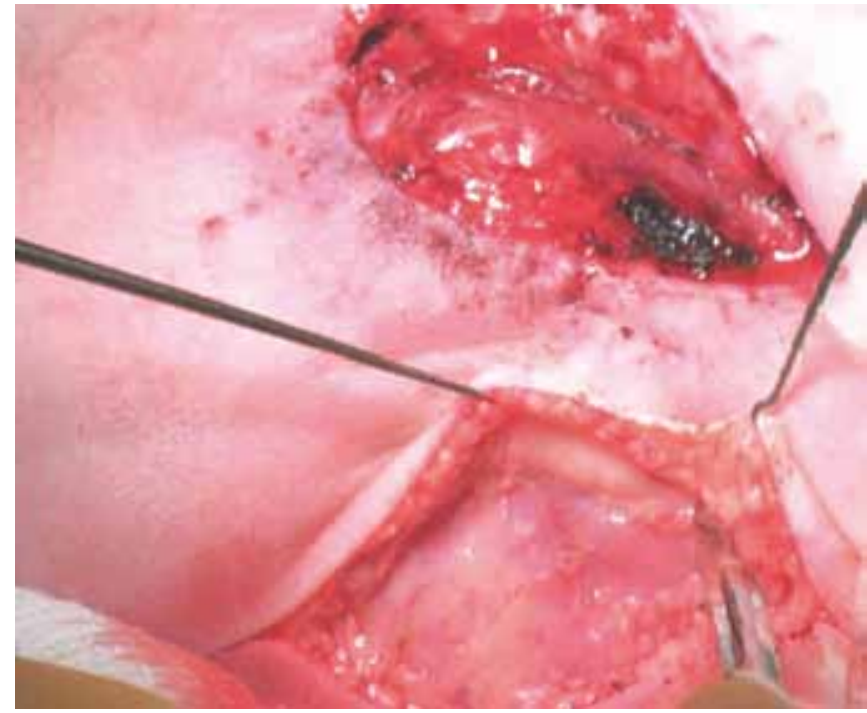

Figura 5 - Descolamento do retalho de lateral para medial em plano subfascial.

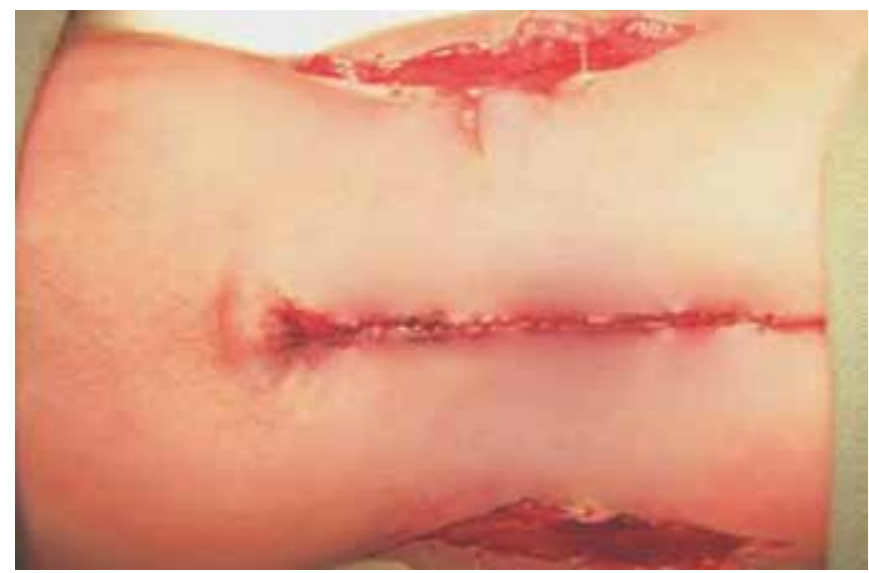

Figura 6 - Retalhos suturados na linha média e fechamento do defeito.

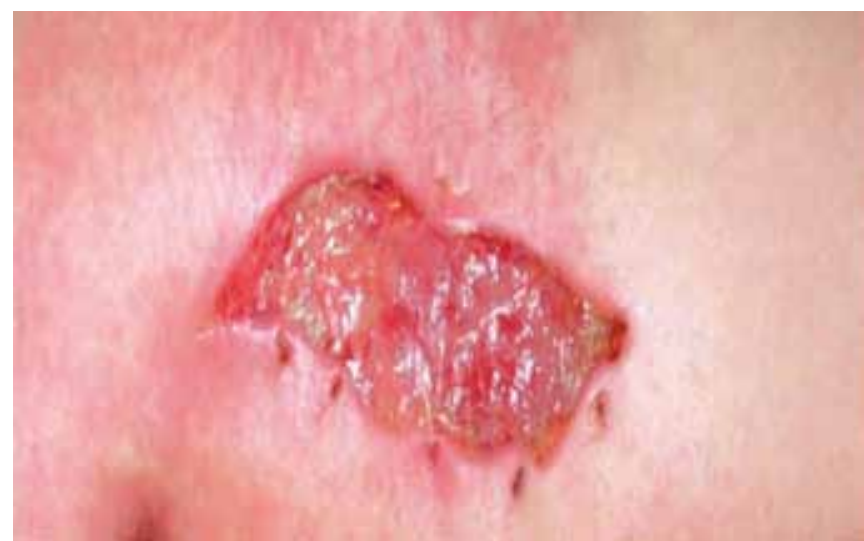

Figura 7 - Foto com detalhe da área cruenta após 5 dias. 


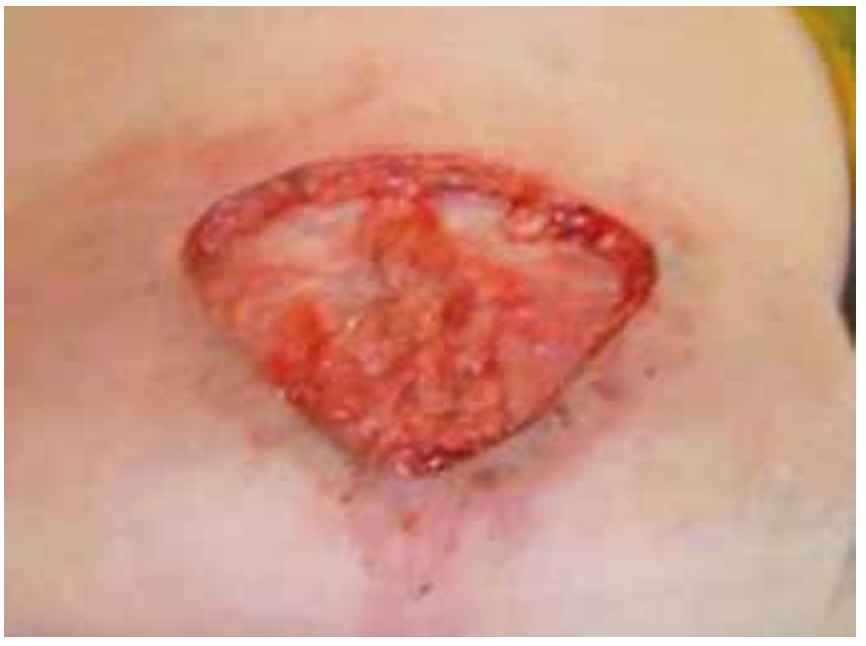

Figura 8 - Aspecto pré-operatório.

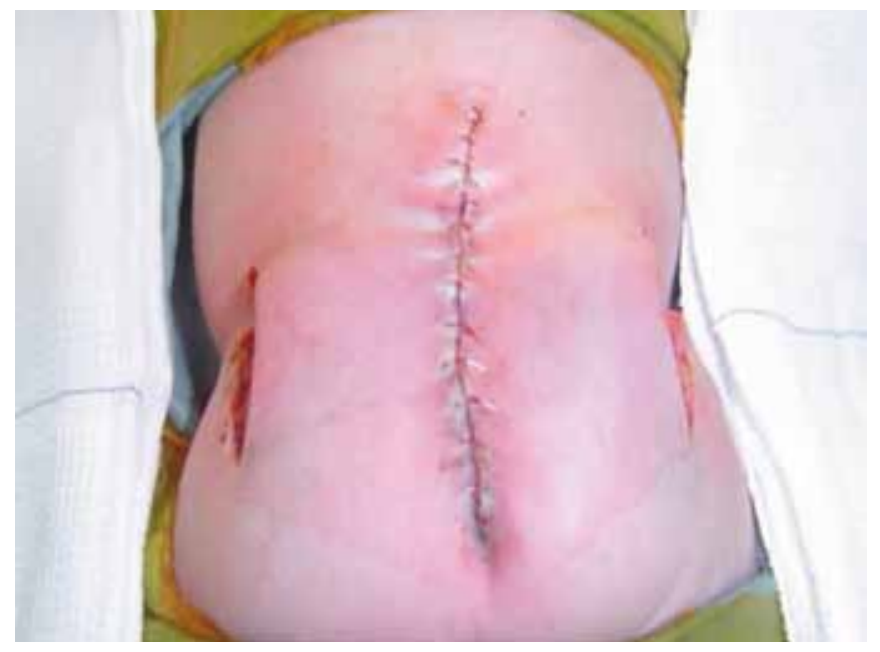

Figura 9 - Aspecto pós-operatório.

- Dissecção dos retalhos no plano subfascial, no sentido lateral para medial, utilizando-se lâmina de bisturi ou tesoura delicada (Figura 5);

- Revisão da hemostasia;

- Avanço medial dos retalhos;

- Síntese em 3 planos (fáscia/subcutâneo/pele) com fio absorvível (poliglecaprone 4.0) (Figura 6);

- Revisão áreas doadoras laterais, que permanecem cruentas para cicatrização por segunda intenção (Figura 7).

\section{RESULTADOS}

Cinco $(55,56 \%)$ dos pacientes eram do sexo feminino e quatro $(44,44 \%)$ do sexo masculino, com $77,78 \%$ do total nascidos a termo. O diagnóstico pré-natal ultrassonográfico

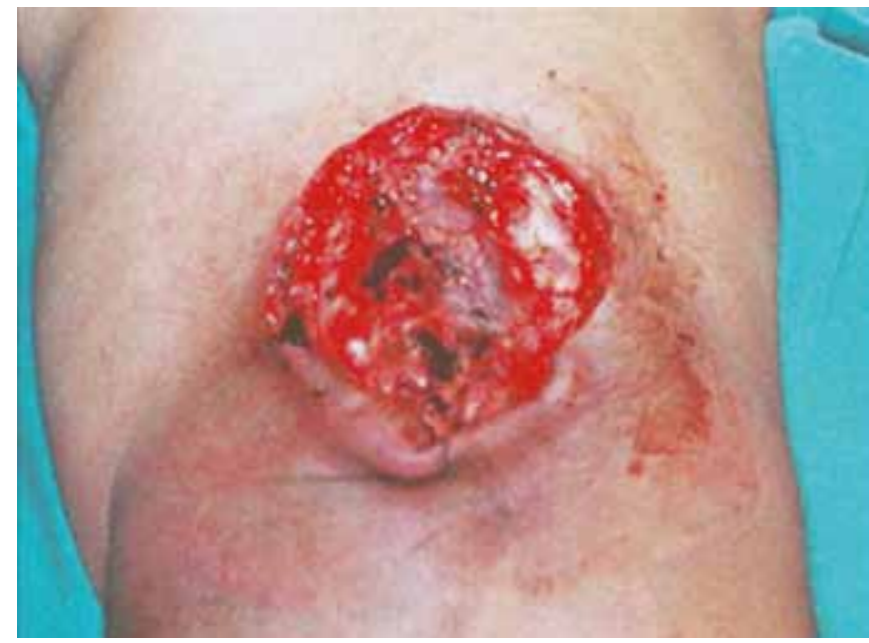

Figura 10 - Aspecto pré-operatório.

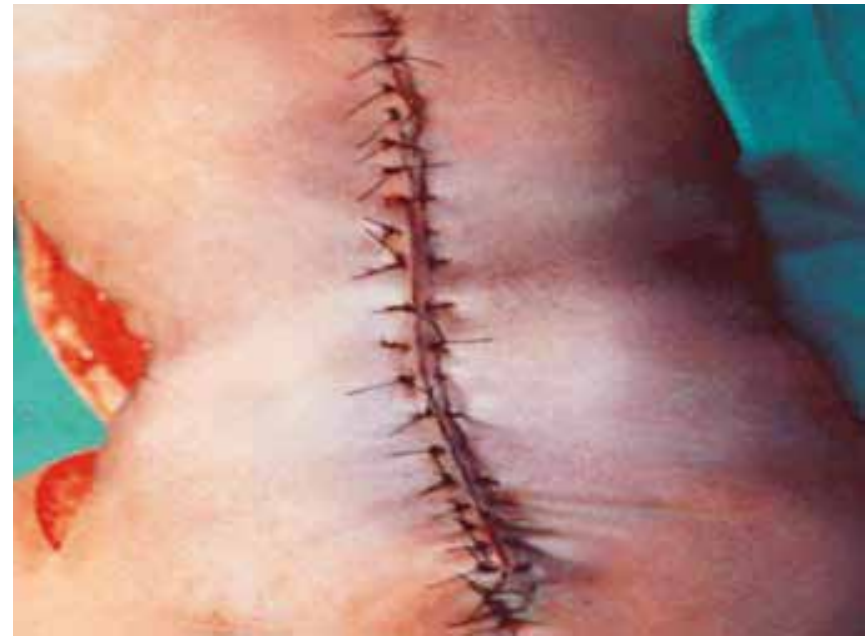

Figura 11 - Aspecto pós-operatório.

foi realizado em 55,56\% dos casos. Quanto à via de parto, em $77,78 \%$ dos pacientes foi o parto cesáreo. Em $66,67 \%$ dos pacientes, a MMGC apresentou-se rota, exigindo urgência no tratamento cirúrgico.

A maioria dos pacientes apresentava malformações associadas $(77,78 \%)$, com maior prevalência de anomalias do trato geniturinário, hidrocefalia e alterações dos membros inferiores.

A principal localização do defeito foi observada na região lombossacra $(77,78 \%)$, seguida da toracolombar $(11,11 \%)$ e torácica $(11,11 \%)$.

O tempo cirúrgico médio foi de 83 minutos para realização da cobertura cutânea, após o término do procedimento neurocirúrgico. Em todos os casos, foi possível o fechamento da lesão com a utilização da técnica apresentada (Figuras 8 a 11). 


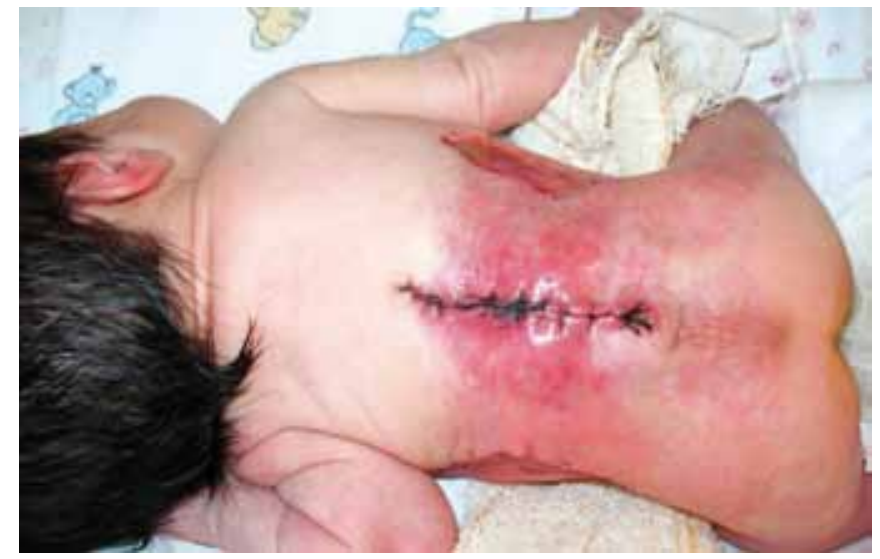

Figura 12 - Pequena área de epiteliólise em terço médio de ferida operatória.

O defeito apresentava área média de $32,1 \mathrm{~cm}^{2}(20-42$ $\mathrm{cm}^{2}$ ). A taxa de complicação pós-operatória relacionada à cirurgia foi de $11,11 \%$ (um caso), representada pela epiteliólise segmentar do retalho na linha média, que foi resolvido por meio de cuidados locais (Figura 12). Não houve casos de infecção ou fístula liquórica.

\section{DISCUSSÃO}

O principal objetivo do reparo da MMGC é a preservação dos elementos neurais expostos e a prevenção dos quadros infecciosos do sistema nervoso central. A intervenção cirúrgica precoce (até 48 horas) é fundamental para um melhor prognóstico neurológico ${ }^{1,2,4,6}$.

A técnica cirúrgica ideal é aquela que promove cobertura completa do defeito, com a utilização de tecidos que apresentem vascularização confiável e que propiciem a formação de um coxim sobre a lesão, para suportar a pressão das proeminências ósseas ${ }^{1,2,5-9}$. Esses objetivos podem ser atingidos com sucesso por meio de uma abordagem multidisciplinar, na qual o neonatologista, o neurocirurgião e o cirurgião plástico têm participação ativa.

O critério para a escolha do método de reconstrução deve basear-se em 3 princípios: (1) condição física do paciente, (2) características do defeito e (3) experiência do cirurgião ${ }^{4}$.

Nos defeitos pequenos, a sutura primária e sem tensão é a melhor conduta. Nos grandes defeitos cutâneos, há preferência pela utilização de retalhos, sejam eles cutâneos, fasciocutâneos, musculares ou musculocutâneos ${ }^{1,2,4-11}$. Os enxertos cutâneos podem ser realizados, no entanto, em longo prazo o índice de complicação é muito alto ${ }^{12}$.

Os retalhos cutâneos (romboides ou zetaplastias) são descritos como técnicas versáteis e simples, com mínimo sangramento. A desvantagem seria a maior chance de isquemia do retalho, em virtude do descolamento amplo e espessura delgada ${ }^{2,5,7}$. Lapid et al. ${ }^{13}$ relataram o uso de retalhos bilobados para tratamento de MMGC, sem complicações, destacando como vantagens a posição distinta entre as linhas de sutura do retalho cutâneo e do reparo neurocirúrgico, mínimo sangramento e menor chance de fístula liquórica.

Os retalhos musculares e musculocutâneos, principalmente do músculo grande dorsal, tem ganho destaque nos últimos anos, podendo ser utilizado como retalho bipediculado $^{8}$, de forma reversa ${ }^{9}$, em avanço $\mathrm{V}-\mathrm{Y}^{14}$ ou distal ${ }^{15}$. As vantagens dos retalhos musculares são a vascularização constante e confiável, a formação de um coxim adequado e a possibilidade de cobertura de grandes lesões. As principais críticas são: tempo cirúrgico prolongado, sangramento mais abundante e a possibilidade de déficit funcional, pela utilização de um músculo importante para a estabilidade da cintura escapular, em pacientes com grande chance de utilização de cadeira de $\operatorname{rodas}^{12,16,17}$.

Frykberg \& Olsen ${ }^{16}$, em 1990, descreveram a utilização de expansores de tecidos em dois pacientes, seguida de rotação dos retalhos, com boa evolução.

Sabe-se que nas correções cirúrgicas em que se utiliza a fáscia como um dos planos do retalho, diminui-se a incidência de coleções de líquido cérebro-espinhal. Iacobucci et al. ${ }^{11}$, em 1996, relataram estudo anatômico e experiência clínica sobre o retalho fasciocutâneo, para fechamento de defeitos amplos, demonstrando que a circulação do retalho provém de três principais pedículos: (1) superiormente por ramos da artéria circunflexa escapular, (2) central, por tributárias das intercostais posteriores e (3) inferiormente por ramos da artéria glútea superior e da artéria circunflexa superficial ilíaca, tratando-se de um retalho seguro.

A escolha do RFCBB nos casos apresentados deve-se à segurança em relação à vascularização, menor tempo cirúrgico, facilidade da dissecção, aplicabilidade e baixo índice de complicações. A principal crítica a esta técnica é a de que o procedimento resulta em duas áreas cruentas laterais, que podem ser enxertadas ou cicatrizar por segunda intenção ${ }^{11}$. Nossa opção por não realizar o enxerto deve-se à observação de que estas áreas cicatrizam em torno de quinze dias, sem o aumento do índice de complicações.

Os achados correspondentes a sexo, tipo de parto, idade gestacional, doenças associadas e localização da MMGC foram semelhantes aos reportados na literatura. Já os índices de MMGC rota $(66,67 \%)$ foram maiores dos que a média encontrada na literatura, cerca de $40 \%{ }^{1,3,17}$. Acreditamos que este fato tenha relação com as baixas condições 
socioeconômicas do grupo estudado, com influência nos cuidados durante a gestação e período perinatal. A média da área do defeito a ser reparado também foi semelhante à encontrada na literatura ${ }^{1,3,11,13,16,17}$.

Não existe consenso em relação ao tipo de parto. Merril et al. ${ }^{18}$, em 1998, compararam o parto normal e a cesáreo, para os pacientes com diagnóstico pré-natal de MMGC, não encontrando diferenças estatísticas que pudessem comprovar melhor prognóstico neurológico, imediato ou tardio, que justificasse a indicação da via de parto cesáreo.

A literatura descreve uma série de opções para o reparo das MMGC, não existindo uma técnica única para todos os tipos de defeito. O cirurgião deve estar familiarizado com uma técnica que possa ser utilizada, na grande maioria dos casos, com alta resolutividade e baixa morbidade.

\section{CONCLUSÃO}

Apesar da existência de várias técnicas descritas na literatura, o fechamento das MMGC permanece um desafio, considerando-se as numerosas variações quanto a tamanho, forma e componentes teciduais do defeito. O RFCBB pode ser considerado como uma boa opção para o tratamento das MMGC, considerando-se a segurança e técnica de realização, com baixo índice de complicações.

\section{REFERÊNCIAS}

1. Plese JPP, Cury VHSS. Disrafismo espinal. In: Diament AJ, Cypel S, eds. Neurologia infantil. $2^{\mathrm{a}}$ ed. Lefèvre: Atheneu;1989. p.676-93.

2. Ulusoy MG, Koçer U, Sungur N, Karaaslan O, Kankaya Y, Ozdemir $\mathrm{R}$, et al. Closure of meningomyelocele defects with bilateral modified V-Y advancement flaps. Ann Plast Surg. 2005;54(6):640-4.

3. Czeizel AE. Periconceptional folic acid and multivitamin supplementation for the prevention of neural tube defects and other congenital abnormalities. Birth Defects Res A Clin Mol Teratol. 2009;85(4):260-8.
4. Chalain TM, Cohen SR, Burstein FD, Hudgins RJ, Boydston WR, O'Brien MS. Decision making in primary surgical repair of myelomeningoceles. Ann Plast Surg. 1995;35(3):272-8.

5. Patterson TJ. The use of rotation flaps following excision of lumbar myelo-meningoceles: an aid to the closure of large defects. Br J Surg. 1959;46:606-8.

6. Ramasastry SS, Cohen M. Soft tissue closure and plastic surgical aspects of large open myelomeningoceles. Neurosurg Clin N Am. 1995;6(2):279-91.

7. Ulusoy MG, Koçer U, Sungur N, Karaaslan O, Kankaya Y, Ozdemir $\mathrm{R}$, et al. Closure of meningomyelocele defects with bilateral modified V-Y advancement flaps. Ann Plast Surg. 2005;54(6):640-4.

8. McCraw JB, Penix JO, Freeman BG, Vincent MP, Wirth FH. Softtissue repair of myelomeningocele defects using bilateral latissimus dorsi and trapezius musculocutaneous flaps. Ann Plast Surg. 1987;18(2):147-55.

9. VanderKolk CA, Adson MH, Stevenson TR. The reverse latissimus dorsi muscle flap for closure of meningomyelocele. Plast Reconstr Surg. 1988;81(3):454-6.

10. Cruz NI, Ariyan S, Duncan CC, Cuono CB. Repair of lumbosacral myelomeningoceles with double Z-rhomboid flaps. Technical note. J Neurosurg. 1983;59(4):714-7.

11. Iacobucci JJ, Marks MW, Argenta LC. Anatomic studies and clinical experience with fasciocutaneous flap closure of large myelomeningoceles. Plast Reconstr Surg. 1996;97(7):1400-8.

12. Mustardé JC. Meningomyelocele: the problem of skin cover. Br J Surg. 1966;53(1):36-41.

13. Lapid O, Rosenberg L, CohenA. Meningomyelocele reconstruction with bilobed flaps. Br J Plast Surg. 2001;54(7):570-2.

14. Hayashi A, Maruyama Y. Bilateral latissimus dorsi V-Y musculocutaneous flap for closure of a large meningomyelocele. Plast Reconstr Surg. 1991;88(3):520-3.

15. Scheflan M, Mehrhof AI Jr, Ward JD. Meningomyelocele closure with distally based latissimus dorsi flap. Plast Reconstr Surg. 1984;73(6):956-9.

16. Frykberg T, Olsen L. Tissue expansion facilitates operation of large myelomeningoceles. Z Kinderchir. 1990;45(4):242-4.

17. Ozçelik D, Yildiz KH, Iş M, Döşoğlu M. Soft tissue closure and plastic surgical aspects of large dorsal myelomeningocele defects (review of techniques). Neurosurg Rev. 2005;28(3):218-25.

18. Merrill DC, Goodwin P, Burson JM, Sato Y, Williamson R, Weiner CP. The optimal route of delivery for fetal meningomyelocele. Am J Obstet Gynecol. 1998;179(1):235-40.
Correspondência para:
Murillo Francisco Pires Fraga

Av. Lineu de Paula Machado, 738 - Cidade Jardim - São Paulo, SP, Brasil - CEP 05601-000

E-mail:murifraga@ig.com.br 